\title{
PENGARUH KOMPENSASI TERHADAP KINERJA KARYAWAN PADA PT. TUNGGAL ABADI DI SERANG, BANTEN
}

\author{
${ }^{1 *}$ Jeffry Adriansyah, ${ }^{2}$ Puji Laksono, ${ }^{3}$ Cecep Warman \\ Sekolah Tinggi Ilmu Ekonomi Banten, Serang, Banten, Indonesia \\ *jeffry.adriansyah0580@gmail.com
}

\begin{abstract}
Abstrak
Penelitian ini bertujuan untuk mengetahui pengaruh kompensasi terhadap kinerja karyawan pada PT. Tunggal Abadi di Serang, Banten. Metode yang digunakan adalah explanatory research dengan sampel sebanyak 98 responden. Teknik analisis menggunakan analisis statistik dengan pengujian regresi, korelasi, determinasi dan uji hipotesis. Hasil penelitian ini variabel kompensasi diperoleh nilai rata-rata skor sebesar 3,415 dengan kriteria baik. Variabel kinerja karyawan diperoleh nilai rata-rata skor sebesar 3,849 dengan kriteria baik. Kompensasi berpengaruh positif dan signifikan terhadap kinerja karyawan dengan nilai persamaan regresi $Y=10,347+0,824 X$, dan nilai koefisien korelasi 0,765 atau memiliki tingkat hubungan yang kuat dengan nilai determinasi 58,5\%. Uji hipotesis diperoleh signifikansi 0,000 $<0,05$.
\end{abstract}

Kata Kunci: Kompensasi, Kinerja Karyawan.

This study aims to determine the effect of compensation on employee performance at PT. Tunggal Abadi in Serang, Banten. The method used is explanatory research with a sample of 98 respondents. The analysis technique uses statistical analysis with regression, correlation, determination and hypothesis testing. The results of this research variable compensation obtained an average score of 3,415 with good criteria. Employee performance variable obtained an average score of 3.849 with good criteria. Compensation has a positive and significant effect on employee performance with the value of the regression equation $Y=10.347+0.824 X$, and the correlation coefficient value of 0.765 or has a strong relationship with a determination value of $58.5 \%$. Hypothesis testing obtained a significance of $0.000<0.05$.

Keywords: Compensation, Employee Performance. 


\section{PENDAHULUAN}

Dengan semakin pesatnya kemajuan teknologi dunia yang saat ini maka semakin ketat juga persaingan bisnis antar organisasi. Berbagai tantangan yang dihadapi oleh perusahaan-perusahaan dalam memasuki era global adalah adanya persaingan bisnis yang berupaya agar masing-masing tetap mampu bersaing dengan kompetitif.

Organisasi dan karyawan merupakan suatu kesatuan yang tak terpisahkan, yang terdiri dari berbagai individu yang memiliki latar belakang kompetensi yang berbeda-beda dan saling bekerja sama satu dengan yang lainnya. Dalam sebuah organisasi, setiap individu didalamnya selalu berusaha mewujudkan tujuan bersama dengan memanfaatkan seluruh sumber daya yang ada. Keberadaan sumber daya manusia yang handal memiliki peran yang lebih strategis dibandingkan sumber daya yang lain.

Suatu organisasi perlu di dukung oleh karyawan yang berkualitas dan profesional. Agar pegawai dapat mempunyai prestasi kerja yang baik, organisasi sangat perlu memperhatikan kompensasi yang diberikan kepada karyawan. Sadar akan pentingnya sumber daya manusia bagi kelangsungan hidup dan kemajuan suatu perusahaan, maka suatu perusahaan harus memberikan perhatian khusus pada faktor produksi ini dan sudah sewajarnya pemilik perusahaan memandang sumber daya manusia lebih dari sekedar aset perusahaan dan menjadikan mitra dalam berusaha. Perusahaan harus dapat bersikap adil atas apa yang telah diberikan oleh sumber daya manusia kepada perusahaan, karena setiap karyawan berhak mendapatkan penghargaan dan perlakuan yang adil dari pimpinannya sebagai timbal balik atas jasa yang diberikannya, sehingga dapat mendorong para karyawan untuk lebih termotivasi dalam menjalankan kewajibannya sebagai seorang pekerja. Hubungan kerja yang saling menguntungkan antara perusahaan dan karyawan sangat diperlukan dalam rangka mendorong semangat kerja karyawan. Karyawan memberikan hasil kerja yang baik untuk kemajuan perusahaan, sedangkan perusahaan memberikan kompensasi yang sesuai atas hasil kerja yang telah diberikan karyawan terhadap perusahaan.

Di dalam organisasi pimpinan harus dapat membina hubungan baik dengan pegawai, dengan cara memberikan insentif, gaji, honor, lembur, bonus dan tunjangan-tunjangan kesejahteraan para pegawai. Karena pada hakekatnya tenaga kerja akan lebih produktif apabila tenaga kerja tersebut menerima gaji dan honor yang seimbang dengan pekerjaan yang telah mereka kerjakan. Namun tunjangantunjangan tersebut tidak diberikan organisasi secara cuma- cuma. Para pegawai harus mampu menunjukkan prestasi yang dimilikinya selama ia bekerja di organisasi tersebut. Gaji, honor, dan insentif tidak saja sekedar cara untuk memuaskan kebutuhan fisik, melainkan juga merupakan pengakuan dan rasa mencapai sesuatu. Gaji dan honor merupakan salah satu alat motivasi untuk bekerja lebih keras dan berdampak dalam mengurangi pergantian pegawai.

Kompensasi merupakan segala sesuatu yang di terima para karyawan sebagai balas jasa untuk pekerjaan mereka. Maksud dari tujuan pemberian kompensasi ini yaitu untuk membantu karyawan memenuhi kebutuhan di luar kebutuhan rasa adil, serta meningkatkan motivasi kerja karyawan dalam menyelesaikan tugas-tugas yang menjadi tanggung jawabnya. Menurut Henry Simamora (2014:442) kompensasi adalah semua bentuk kembalian finansial, jasajasa terwujud dan tunjangan yang di peroleh karyawan sebagai bagian dari hubungan kekaryawanan. Sedangkan menurut Hasibuan (2014:118) Kompensasi adalah semua pendapatan yang berbentuk uang, barang langsung atau tidak langsung yang diterima karyawan sebagai imbalan atas jasa yang diberikan kepada perusahaan. 
PT. Tunggal Abadi merupakan salah satu perusahaan yang bergerak dibidang penyediaan bahan baku biji plastik yang selama ini konsentrasi bisnisnya menggarap pada pemenuhan perusahaan yang membuat fiber atap maupun kanopi dalam pembangunan rumah atau ruko maupun gedung.

Berdasarkan data survey dilapangan perusahaan memiliki kendala yaitu semakin menurunnya target penyelesaian pekerjaan pembangunan rumah. Hal ini disinyalir sebagai akibat pemberian kompensasi yang belum sepenuhnya dijalankan secara baik oleh perusahaan.

Dengan kompensasi yang diterima maka karyawan akan termotivasi untuk bekerja dengan sebaik-baiknya dan penuh tanggung jawab sehingga prestasi kerja meningkat. Semakin meningkatnya kinerja karyawan akan semakin menguntungkan bagi karyawan dan perusahaan sehingga dapat bersaing. Dengan pemberian kompensasi yang sesuai dengan peraturan yang berlaku bisa jadi mampu meningkatkan semangat karyawan dalam menjalankan tugas dan kewajibannya.

Kinerja dapat mempengaruhi berlangsungnya kegiatan suatu organisasi. Semakin baik kinerja yang ditunjukkan oleh para karyawan akan sangat membantu dalam perkembangan organisasi tersebut. Menurut Mangkunegara (2013:67) kinerja adalah hasil kerja secara kualitas dan kuantitas yang di capai oleh seorang pegawai dalam melaksanakan tugasnya sesuai dengan tanggung jawab yang diberikan kepadanya. alah satu cara untuk memotivasi mereka guna dapat meningkatkan kinerja karyawan adalah dengan cara memberikan kompensasi kepada mereka. Hal ini diharapkan akan tercipta pola hubungan yang baik antara karyawan dengan perusahaan dimana karyawan akan berfikir tempat mereka bekerja dapat memahami serta damemenuhi kebutuhan hidup yang menjadi pemicu mengapa mereka bekerja.

Berdasarkan uraian yang telah dijelaskan diatas, penulis tertarik untuk melakukan penelitian yang lebih mendalam dengan judul "Pengaruh Kompensasi Terhadap Kinerja Karyawan Pada PT. Tunggal Abadi di Jakarta".

\section{TINJAUAN PUSTAKA}

\section{Kompensasi}

Yang di maksud dengan kompensasi dalam penelitian ini adalah balas jasa yang diberikan perusahaan terhadap karyawan baik yang berbentuk uang atau barang, langsung maupun tidak langsung. Menurut Hendry Simamora (2014:442) kompensasi adalah semua bentuk kembalian finansial, jasa-jasa terwujud dan tunjangan yang di peroleh karyawan sebagai bagian dari hubungan kekaryawan.

2. Kinerja Karyawan

Yang di maksud dengan kinerja pada penelitian ini adalah hasil kerja secara kualitas dan kuantitas yang di capai oleh seorang karyawan dalam melaksanakan tugasnya sesuai dengan tanggung jawab yang diberikan kepadanya. Menurut Mangkunegara (2013:67) kineja adalah hasil kerja secara kulitas dan kuantitas yang di capai oleh seorang pegawai dalam melaksanakan tugasnya sesuai dengan tangung jawab yang diberikan kepadanya.

\section{METODE PENELITIAN}

\section{Populasi}

Populasi dalam penelitian ini berjumlah 98 responden PT. Tunggal Abadi di Serang, Banten

\section{Sampel}

Teknik pengambilan sampling dalam penelitian ini adalah sampel jenuh, dimana semua anggota populasi dijadikan sebagai sampel. Dengan demikian sampel dalam penelitian ini sampel yang digunakan berjumlah 98 responden.

\section{Jenis Penelitian}

Jenis penelitian yang dipakai adalah asosiatif, dimana tujuannya adalah untuk mengetahui atau mencari keterhubungan antara variabel 
independen terhadap variabel dependennya

\section{Metode Analisis Data}

Dalam menganalisis data digunakan uji validitas, uji reliabilitas, analisis regresi linier sederhana, analisis koefisien korelasi, analisis koefisien determinasi dan pengujian hipotesis.

\section{HASIL PENELITIAN}

1. Analisis Deskriptif

Pada pengujian ini digunakan untuk mengetahui skor minimum dan maksimum skor tertinggi, ratting score dan standar deviasi dari masing-masing variabel. Adapun hasilnya sebagai berikut:

Tabel 1. Hasil Analisis Descriptive Statistics

Descriptive Statistics

$\mathrm{N}$ Minimum Maximum Mean Std. Deviation

\begin{tabular}{l|r|r|r|r|r|}
\hline Kompensasi (X) & 98 & 28 & 44 & 34.15 & 3.835 \\
\hline Kinerja Karyawan (Y) & 98 & 29 & 49 & 38.49 & 4.132 \\
\hline Valid N (listwise) & 98 & & & & \\
\hline
\end{tabular}

Kompensasi diperoleh varians minimum sebesar 28 dan varians maximum 44 dengan ratting score sebesar 3,415 dengan standar deviasi 3,835. Skor ini termasuk pada rentang sakala 3,40 4,19 dengan kriteria baik atau setuju.

Kinerja karyawan diperoleh varians minimum sebesar 29 dan varians maximum 49 dengan ratting score sebesar 3,849 dengan standar deviasi 3,499. Skor ini termasuk pada rentang sakala 3,40 4,19 dengan kriteria baik atau setuju.

\section{Analisis Kuantitatif}

Pada analisis ini dimaksudkan untuk mengetahui pengaruh variabel independen terhadap variabel dependen. Adapun hasil pengujian sebagai berikut:

a. Analisis Regresi Linier Sederhana

Uji regresi ini dimaksudkan untuk mengetahui perubahan variabel dependen jika variabel independen mengalami perubahan. Adapun hasil pengujiannya sebagai berikut:

Tabel 2. Hasil Pengujian Regresi Linier Sederhana

\section{Coefficients ${ }^{\mathrm{a}}$}

Unstandardized Coefficients Standardized Coefficients

\begin{tabular}{|c|c|c|c|c|c|}
\hline Model & B & Std. Error & Beta & $\mathrm{t}$ & Sig. \\
\hline 1 (Constant) & 10.347 & 2.435 & & 4.249 & .000 \\
\hline Kompensasi $(X)$ & .824 & .071 & .765 & 11.629 & .000 \\
\hline
\end{tabular}

a. Dependent Variable: Kinerja Karyawan $(\mathrm{Y})$

Berdasarkan hasil pengujian pada tabel di atas, diperoleh persamaan regresi $\mathrm{Y}=10,347+$ 0,824X. Dari persamaan tersebut dijelaskan sebagai berikut:

1) Konstanta sebesar 10,347 diartikan jika kompensasi tidak ada, maka telah terdapat nilai kinerja karyawan sebesar 10,347 point.

2) Koefisien regresi kompensasi sebesar 0,824, angka ini positif artinya setiap ada peningkatan kompensasi sebesar 0,824 point maka kinerja karyawan juga akan mengalami peningkatan sebesar 0,824 point.

\section{b. Analisis Koefisien Korelasi}

Analisis koefisien korelasi dimaksudkan untuk mengetahui tingkat kekuatan hubungan dari variabel independen terhadap variabel dependen. Adapun hasil pengujian sebagai berikut: 
Tabel 3. Hasil Pengujian Koefisien Korelasi Kompensasi Terhadap Kinerja Karyawan. Correlations $^{\mathrm{b}}$ Kompensasi (X) Kinerja Karyawan (Y)

\begin{tabular}{llr|r}
\hline Kompensasi (X) & Pearson Correlation & 1 & $.765^{* *}$ \\
\cline { 2 - 4 } & Sig. (2-tailed) & & .000 \\
\hline Kinerja Karyawan (Y) & Pearson Correlation & $.765^{* *}$ & 1 \\
\cline { 2 - 4 } & Sig. (2-tailed) & .000 & \\
\hline \multirow{2}{**}{ *. Correlation is significant at the 0.01 level (2-tailed). } & & \\
b. Listwise N=98 & & &
\end{tabular}

Berdasarkan hasil pengujian diperoleh nilai korelasi sebesar 0,765 artinya kompensasi memiliki hubungan yang kuat terhadap kinerja karyawan. c. Analisis Koefisien Determinasi

Analisis koefisien determinasi dimaksudkan untuk mengetahui besarnya persentase pengaruh dari variabel independen terhadap variabel dependen. Adapun hasil pengujian sebagai berikut:

Tabel 4. Hasil Pengujian Koefisien Determinasi Kompensasi Terhadap Kinerja

Karyawan.

Model Summary

\begin{tabular}{lr|r|r|r} 
Model & R & R Square & Adjusted R Square & Std. Error of the Estimate \\
\hline 1 & $.765^{\mathrm{a}}$ & .585 & .581 & 2.677 \\
\hline
\end{tabular}

a. Predictors: (Constant), Kompensasi (X)

Berdasarkan hasil pengujian diperoleh nilai determinasi sebesar 0,585 artinya kompensasi memiliki kontribusi pengaruh sebesar 58,5\% terhadap kinerja karyawan, sedangkan sisanya sebesar $41,5 \%$ dipengaruhi oleh faktor lain yang tidak dilakukan penelitian.

Tabel 5. Hasil Uji Hipotesis Kompensasi Terhadap Kinerja Karyawan.

\section{Coefficients ${ }^{a}$}

Unstandardized Coefficients Standardized Coefficients

\begin{tabular}{|c|c|c|c|c|c|}
\hline Model & B & Std. Error & Beta & $\mathrm{t}$ & Sig. \\
\hline 1 (Constant) & 10.347 & 2.435 & & 4.249 & .000 \\
\hline Kompensasi (X) & .824 & .071 & .765 & 11.629 & .000 \\
\hline
\end{tabular}

a. Dependent Variable: Kinerja Karyawan (Y)

Berdasarkan hasil pengujian pada tabel di atas, diperoleh nilai $\mathrm{t}$ hitung $>\mathrm{t}$ tabel atau $(7,809>1,985)$, dengan demikian hipotesis yang diajukan bahwa terdapat pengaruh yang signifikan atara kompensasi terhadap kinerja karyawan diterima.

\section{PEMBAHASAN HASIL PENELITIAN}

1. Kondisi Jawaban Responden Variabel Kompensasi

Berdasarkan jawaban responden,

\section{d. Uji Hipotesis}

Pengujian hipotesis dengan uji $\mathrm{t}$ digunakan untuk mengetahui hipotesis mana yang diterima.

Rumusan hipotesis: Terdapat pengaruh yang signifikan kompensasi terhadap kinerja karyawan. 


\section{Pengaruh Kompensasi Terhadap Kinerja Karyawan \\ berpengaruh}

Kompensasi

signifikan terhadap kinerja karyawan dengan persamaan regresi $Y=10,347+$ $0,824 X$, nilai korelasi sebesar 0,765 atau memiliki hubungan yang kuat dengan kontribusi pengaruh sebesar 58,5\%. Pengujian hipotesis diperoleh nilai $t$ hitung $>\mathrm{t}$ tabel atau $(7,809>1,985)$. Dengan demikian hipotesis yang diajukan bahwa terdapat berpengaruh signifikan antara kompensasi terhadap kinerja karyawan diterima.

\section{PENUTUP}

\section{Kesimpulan}

a. Variabel kompensasi diperoleh ratting score sebesar 3,415 berada di rentang skala 3,40 - 4,19 dengan kriteria baik atau setuju.

b. Variabel kinerja karyawan diperoleh ratting score sebesar 3,849 berada di rentang skala 3,40 - 4,19 dengan kriteria baik atau setuju.

c. Kompensasi berpengaruh signifikan terhadap kinerja karyawan dengan persamaan regresi $\mathrm{Y}=10,347+0,824 \mathrm{X}$, nilai korelasi sebesar 0,765 atau kuat dan kontribusi pengaruh sebesar 58,5\% sedangkan sisanya sebesar 41,5\% dipengaruhi faktor lain. Uji hipotesis diperoleh nilai $\mathrm{t}$ hitung $>\mathrm{t}$ tabel atau $(7,809>1,985)$.

\section{Saran}

a. Perusahaan harus mampu melakukan perbaikan terkait dengan pengupahan dan standar penggajian yang mengacu pada peraturan pemerintah

b. Kinerja perusahaan dapat ditingkatkan dengan memberdayakan karyawan dengan menegakkan peraturan yang baik dan pemberian motivasi yang lebih inten lagi.

\section{DAFTAR PUSTAKA}

Affandi, A., Sarwani, A. S., Erlangga, H., Siagian, A. O., Purwanto, A., Effendy, A. A., ... \& Wahyitno, C. D. M. (2020).
Optimization of MSMEs Empowerment in Facing Competition in the Global Market during the COVID-19 Pandemic Time. Systematic Reviews in Pharmacy, 11(11), 1506-1515. Algifari. (2015). “Analisis Regresi untuk Bisnis dan Ekonomi". Yogyakarta: BPFE.

Arikunto, Suharsimi (2014). "Prosedur Penelitian Suatu Pendekatan Praktek". Jakarta: Rineka Cipta.

Bangun, Wilson. 2012. "Manajemen Sumber Daya Manusia". Jakarta: Erlangga

Bejo Siswanto (2013) Manajemen Tenaga Kerja Rancangan dalam Pendayagunaan dan Pengembangan Unsur Tenaga Kerja", Bandung: Sinar Baru.

Dessler, G. (2006.) Manajemen Sumber Daya Manusia (Jilid II). Jakarta: Indeks.

Edi Sutrisno (2016). Manajemen Sumber Daya Manusia. Jakarta: Prenadamedia Group.

George Terry R \& Rue, Leslie W. Rue (2016) Dasar-Dasar Manajemen, Jakarta Bumi Aksara.

Gerry Dessler (2016) Human Resources Management, Prenticehall, London: International Inc.

Handoko (2016) Manajemen Personalia dan Sumberdaya Manusia. Yogyakarta: BPFE.

Hasibuan, Malayu S.P. (2016). Manajemen Sumber Daya Manusia. Edisi Revisi. Jakarta: PT Bumi Aksara.

Imam Ghozali (2017). "Aplikasi Analisis Multivariate Dengan Program SPSS". Edisi Kelima. Semarang: Badan Penerbit Undip.

Jasmani, J., \& Paeno, P. (2019). The Effect of Leadership and Competence on Lecturer Performance and Its Implications on Student Learning Motivation at Pamulang University. International Journal of Advances in Social and Economics, 1(4).

. (2020). The Influence of Product Mix, Promotion Mix and Brand Image on Consumer Purchasing Decisions of Sari Roti Products in South Tangerang. PINISI Discretion Review, 1(1), 165-174. 
Luthans Fred (2014) Organizational Behavior, Ney York: McGraw-Hill, New York.

Mangkunegara, Prabu Anwar. (2016). Evaluasi Kinerja SDM. Cetakan ke tujuh, PT Refika Aditama: Bandung.

Muslimat, A., Muhsin, H., Wahid, H. A., Yulistiana, I., Sunarsi, D., Dewi, K., ... \& Ilham, D. (2021). Develop Technology Based Multimedia For Indonesian Teachers. Journal of Contemporary Issues in Business and Government, 27(1), 1871-1882.

Purwanti, Y. (2021). The Influence Of Digital Marketing \& Innovasion On The School Performance. Turkish Journal of Computer and Mathematics Education (TURCOMAT), 12(7), 118127.

Muslimat, A. (2021). Masa Depan Kampus Merdeka \& Merdeka Belajar: Sebuah Bunga Rampai Dosen. Bintang Visitama Publisher.

Nurjaya, N., Affandi, A., Ilham, D., Jasmani, J., \& Sunarsi, D. (2021). Pengaruh Kompetensi Sumber Daya Manusia Dan Kemampuan Pemanfaatan Teknologi Terhadap Kinerja Aparatur Desa Pada Kantor Kepala Desa Di Kabupaten Gunungkidul, Yogyakarta. JENIUS (Jurnal Ilmiah Manajemen Sumber Daya Manusia), 4(3), 332-346.

Prasada, D., Sunarsi, D., \& Teriyan, A. (2020). Pengaruh Etos Kerja Dan Kompensasi Terhadap Komitmen
Organisasi Pada DHL Logistic Di Jakarta. JENIUS (Jurnal Ilmiah Manajemen Sumber Daya Manusia), 4(1), 51-60.

Robbins, P.S, \& Judge, A.T. (2003). Organizational Behavior. Jakarta: Salemba Empat.

Sedarmayanti (2016) Manajemen Sumber Daya Manusia, Reformasi Birokrasi dan Manajemen Karyawan Negeri Sipil, Cetakan Kelima, Bandung: PT Refika Aditama.

Sudjana (2014) "Metode Statistika", Bandung: Tarsido.

Sugiyono (2017), "Metode Penelitian Administrasi : dilengkapi dengan Metode $R \mathcal{E} D^{\prime \prime}$. Bandung: Alfabeta.

Sunarsi, D. (2017). Pengaruh Kepemimpinan Dan Budaya Organisasi terhadap Kinerja Karyawan Pada Cabang Pembantu Bank DKI Pondok Labu-Jakarta Selatan. JENIUS, 1(2), 21. (2020). The Influence of Supply Chain Strategy on Employee Performance on Small and Medium Business in Beringharjo Market, Yogyakarta-Indonesia. International Journal of Supply Chain Management, 9(5).

Veithzal Rivai (2015) Manajemen Sumber Daya Manusia Untuk Perusahaan, Jakarta: Raja Grafindo Persada.

Wibowo (2015) Manajemen Kinerja, Jakarta: PT. Raja Grafindo Persada. 